\title{
High Precision Coulometric Titration of Uranium
}

\author{
George Marinenko, William F. Koch, and Edgar S. Etz* \\ National Bureau of Standards, Washington, DC 20234 \\ December 20, 1982
}

\begin{abstract}
An improved method for the coulometric assay of uranium and uranium oxide has been developed based on the electrogeneration of $\mathrm{Ti}(\mathrm{HH})$ in $\mathrm{H}_{2} \mathrm{SO}_{4}$, using $\mathrm{Fe}(\mathrm{H})$ as a catalyst. The endpoint is determined amperometrically. Hydrogen peroxide is used as the oxidant in the dissolution of the uranium to avoid interferences from nitrate. The precision of the method as indicated by the standard deviation of an individual observation ranged from 0.008 weight percent for the analysis of the metal to 0.02 weight percent for the analysis of the oxides.
\end{abstract}

Key words: amperometry; coulometric titration; electrogeneration; high-precision coulometry; hydrogen peroxide; standard reference material; titanium; titanous ion; uranium; uranium oxide.

\section{Infroduction}

Coulometry is an absolute method of analysis based on Faraday's Laws of Electrolysis which relate electric current $(i)$, time $(t)$, and chemical equivalent weight (mole) through the equation:

$$
\text { mole }=\frac{1}{\mathbf{F}} \int_{\mathrm{o}} t_{i \mathrm{~d} t} .
$$

The constant of proportionality, $F$, is the Faraday, the exact value of which has been the subject of intense research over the years at the National Bureau of Standards (NBS) [1-4] $]^{1}$. The parameters which define the analytical system are based on measurements of physical quantities, the national standards of which are maintained by NBS, i.e., volt, ohm, second, and gram.

This paper is another from a series of investigations designed to develop highly precise and accurate analytical procedures based upon the coulometric technique. Earlier papers have described the coulometric titrations of acids and bases [5], halides [6], and potassium dichromate [7]. The method described here has been developed for highprecision analysis of uranium metal and its compounds, which are of great scientific, industrial, and commercial importance. Some portions of this investigation have been previously reported at the 1965 EURATOM Conference

*All three authors are with the Center for Analytical Chemistry in NBS' National Measurement Laboratory.

'Figures in brackets indicate literature references at the end of this paper. on High Precision Analysis of Substances of Interest to Nuclear Energy [8].

Among the multitude of existing methods for analysis of uranium, only a few are sufficiently precise for assaying relatively high purity materials. The classical methods involve preliminary reduction of uranyl ion to a mixture of tri- and tetravalent uranium by either passing it through a Jones reductor or reducing the uranyl ion at a mercury or gold amalgam cathode, followed by air oxidation of U(III) to U(IV) and finally oxidation of U(IV) to U(VI) with an oxidant such as $\mathrm{K}_{2} \mathrm{Cr}_{2} \mathrm{O}_{7}[9,10]$. One variation involves potentiometric titration of a mixture of trivalent and tetravalent uranium (obtained from a Jones reductor) first to U(III) - U(IV) endpoint and then to U(IV) - U(VI) endpoint. The uranium content is calculated from the difference between the two endpoints [11]. In another variation, U(III) - U(IV) mixture is titrated potentiometrically to the first endpoint, then solid dichromate is added in excess and the excess dichromate is determined coulometrically [12]. Another method involves the dissolution of uranium metal in orthophosphoric acid, followed by a titration with dichromate using no prereduction [13]. Recently a precise titrimetric method for uranium was reported by Leon Pszonicki [14]. In this method $U(V I)$ is reduced to $U($ III) in hydrochloric acid solution, using an amalgamated cadmium reductor. Orthophosphoric acid is used to oxidize U(III) to U(IV) followed by quantitative oxidation with dichromate to U(VI). All of the aforementioned procedures involve the use of potassium dichromate as the quantitative oxidant converting $U(I V)$ to $U(V I)$. Most require pre-reduction 
and pre-titration steps to prepare the analyte for the actual assay.

An alternative to the oxidative assay of U(IV) to U(VI) is one based on a quantifiable reduction of U(VI) to U(IV). Such a procedure requires a strong reductant obtainable in a purified and stable form and deliverable in discrete quantities during the course of a titration. Of the possible chemical species meeting these requirements, titanous ion (Ti(III)) has proved to be the reductant of choice for this application. Several articles have been written describing conditions for the generation of $\mathrm{Ti}$ (III) [15-17]. The first successful coulometric titration method for uranium with the use of electrogenerated $\mathrm{Ti}(\mathrm{III})$ was reported by Lingane and Iwamoto [18]. This method uses a mercury-pool cathode at elevated temperatures to effect complete and efficient reaction.

Kennedy and Lingane proposed another coulometric procedure employing a platinum cathode and a catalyst. Their procedure was intended to circumvent the drawbacks associated with a mercury cathode and high temperatures $[19,20]$. In the present paper, a method based on the work of Kennedy and Lingane is described. The existing procedure has been refined to improve the precision and accuracy of the assay of uranium and to make it applicable to the certification of Standard Reference Materials (SRMs).

\section{Summary of Method}

The method is based on the coulometric reduction of hexavalent uranium, U(VI), to the tetravalent state, U(IV), using titanous ion, Ti(III), as the intermediate reductant and $\mathrm{Fe}(\mathrm{II})$ as a catalyst. This reduction takes place in a solution of $1 \mathrm{~mol} / \mathrm{L}$ titanyl sulfate and $9 \mathrm{~mol} / \mathrm{L}$ sulfuric acid at a platinum cathode in the controlledcurrent mode. The current density of the cathode is maintained at or below $2.5 \mathrm{~mA} / \mathrm{cm}^{2}$. The standard potentials of the reduction reactions are:

$$
\begin{aligned}
& \mathrm{UO}_{2}{ }^{2+}+4 \mathrm{H}^{+}+2 \mathrm{e}=\mathrm{U}^{4+}+2 \mathrm{H}_{2} 0 \mathrm{E}^{0}=+0.334 \\
& \mathrm{Ti}^{2+}+2 \mathrm{H}^{+}+\mathrm{e}=\mathrm{Ti}^{3+}+\mathrm{H}_{2} \mathbf{0} \quad E^{0}=+0.1 \\
& \mathrm{Fe}^{\mathrm{j}+}+\mathrm{e} \quad=\mathrm{Fe}^{2+} \quad E^{\mathrm{o}}=+0.771 \text {. }
\end{aligned}
$$

At the beginning of the titration, direct reduction of $U(V I)$ to $U(I V)$ is the principal cathodic reaction. As the uranyl ion concentration is depleted, coreduction of titanyl ion begins. The generated titanous ion in turn acts as a reductant for the remaining uranyl ion in the bulk of the solution. Finally, as the endpoint is approached, titanous ion generation becomes the principal cathodic reaction. Under these conditions, the overall reduction of U(VI) to U(IV) occurs with 100 percent current efficiency.
To add further complexity to the reduction process, it has been reported by various authors, and verified in our laboratory, that the rate of reduction of U(VI) by Ti(III) is a slow process. Lingane and Kennedy [19] pointed out that in a sulfuric acid medium the reduction of U(VI) to U(V) proceeds rapidly, but further reduction to U(IV) is the slow and rate-determining step. They found that small amounts of ferrous ion catalyze the reduction of $U(V)$ to U(IV) facilitating the titration at room temperature. Ferrous ion reduces $U(V)$ to $U(I V)$ more rapidly than does $\mathrm{Ti}(\mathrm{III})$ and in turn the ferric ion produced in this reaction is reduced relatively rapidly by the trivalent titanium.

Unfortunately, even in the presence of ferrous ion, the kinetics of this reaction are not sufficiently favorable for high precision work. The approach to equilibrium is slow. The rate expression derived by Kennedy and Lingane for this reaction in a sulfuric acid medium is:

$$
\frac{-\mathrm{d}[\mathrm{Ti}(\mathrm{III})]}{\mathrm{d} t}=k \frac{[\mathrm{Ti}(\mathrm{III})]^{2}}{[\mathrm{TU}(\mathrm{VI})]}
$$

It is apparent that since the rate of the reaction is of the first order with respect to U(VI) concentration and of the second order with respect to Ti(III) concentration, the equilibrium is established more rapidly in the presence of excess Ti(II). Accordingly, it is advantageous to overtitrate by generating a slight excess of Ti(III) and then, when equilibrium is established, to extrapolate back to the equivalence point after determining the response factor of the indicator electrode.

The principal modifications to the method which are described in the paper and which have resulted in increased precision and accuracy are:

- a more stable endpoint detection system composed of a platinum versus saturated calomel electrode pair in the amperometric mode, rather than the dual platinum biamperometric technique;

- highly stable and accurate current-controllers and timing circuitry to assure accurate integration of charge;

- improved dissolution procedures for uranium metal and oxides;

- overtitration to improve the kinetics at the endpoint.

\section{Experimental}

\subsection{Apparatus}

The apparatus used in this work is described in detail in previous publications [2,21-24]. The constant-current sources are of two types. The first employs a commercially-available power supply operated in the 
constant-current mode. The instrument has a maximum output of $60 \mathrm{~V}$ and a current rating of 0 to $2 \mathrm{~A}$. The stability of this power supply is on the order of 0.001 percent per 8 hours and its reliability proven through its use in high-precision coulometric iodimetry $[21]$ and on the determinations of the atomic weights of gallium [22] and zinc [23]. The second type of current-source, used in the later stages of this experiment, was designed and built at NBS in connection with a redetermination of the Faraday via 4-aminopyridine [24]. It is powered by batteries to minimize problems associated with ac ripple and ground loops and is stable to better than 0.001 percent per 8 hours.

The output of either current source is adjusted such that the current flowing through a standard resistor (which is in series with the coulometric titration cell) produces a potential equal to the emf of a Weston saturated cell. Balance is monitored with a null-point detector such as a microvoltmeter or galvanometer, and maintained manually.

The standard resistors are of the NBS-type, devoid of their metal containers and immersed in a large oil-bath to ensure temperature stability. The Weston saturated cells were enclosed in a thermostated box. The cells and resistors are periodically calibrated against the national working standards of voltage and resistance maintained at NBS. A commercially available electronic frequency meter was used as the timer, its operational mode set to count the cycles of the NBS $10 \mathrm{kHz}$ standard frequency. The current-source and timer are integrated through a switching system, designed and built at NBS. In the standby position, the current flows through a surrogate load resistor comparable in resistance to that of the titration cell, and the timer gate is open; in the active position, the current is channeled to the titration cell, and the timer gate is closed.

The titration cell, similar to one used in previous highprecision coulometric research at NBS [2], is constructed of two $180 \mathrm{~mL}$ tall-form beakers connected by two intermediate chambers with fritted-glass separaters. A silicic acid gel plug was prepared in the last compartment of the titration $\mathrm{H}$-cell by mixing sodium silicate solution with sulfuric acid directly in the compartment. The volumes of solutions used in gel preparation were selected such that the amount of gel produced would fill one-half of the 180 $\mathrm{mL}$ beaker, completely covering the glass frit of the connecting chamber. Sulfuric acid $(2 \mathrm{~mol} / \mathrm{L})$ was poured over the silicic acid plug. The titration cell was further extended through a $\mathrm{U}$ tube, containing another silicic acid plug, to a $180 \mathrm{~mL}$ beaker filled with saturated $\mathrm{KCl}$ solution and serving as the anode compartment. The saturated calomel reference electrode of the indicator circuit was also dipped into this compartment.
A modified cage-type platinum electrode was used as the cathode. It consisted of a platinum foil cylinder concentrically located within a platinum strip cage. The apparent area of the former was $28 \mathrm{~cm}^{2}$, and of the latter $12 \mathrm{~cm}^{2}$, yielding a total area of $40 \mathrm{~cm}^{2}$. Early experiments showed that the platinum cathode will perform less than satisfactorily if its surface is not properly prepared. Consequently the conditioning procedure described below was scrupulously followed:

a) store the electrode each night in a solution of 1 $\mathrm{mol} / \mathrm{L} \mathrm{K}_{2} \mathrm{Cr}_{2} \mathrm{O}_{7}$ and $2 \mathrm{~mol} / \mathrm{L} \mathrm{H}_{2} \mathrm{SO}_{4}$

b) rinse with distilled water and soak in a solution of $0.1 \mathrm{~mol} / \mathrm{L}$ ferrous ammonium sulfate and $2 \mathrm{~mol} / \mathrm{L}$ $\mathrm{H}_{2} \mathrm{SO}_{4}$

c) rinse thoroughly with distilled water and install in titration cell.

After several titrations, it was sometimes necessary to strip the surface of the electrode by dipping it in aqua regia for 5 minutes and then reconditioning it according to the above procedure. The anode was a silver cylinder made from $2 \mathrm{~mm}$ thick foil and having a surface area of $100 \mathrm{~cm}^{2}$.

The amperometric indicator system consisted of a platinum foil electrode $\left(1 \mathrm{~cm}^{2}\right)$ and a saturated calomel electrode (SCE) with a flushable liquid junction. A polarograph was used as the source of the applied emf as well as for recording the indicator current. The value of applied emf was determined by running a currentvoltage scan using the indicator electrode versus the SCE in the titration cell containing a solution similar to that expected at the equivalence point of an actual titration (Figure 1). The flat portion of this voltammogram typically extended from about +0.2 to $+0.3 \mathrm{~V}$ versus SCE, which represents the useable window for the applied emf. Since this window is rather narrow (due to the oxidation of $\mathrm{Fe}(\mathrm{II})$ at voltages more positive than $+0.3 \mathrm{~V}$ and the reduction of $\mathrm{Ti}(\mathrm{IV})$ at voltages below $+0.2 \mathrm{~V}$ ) and has a tendency to shift slightly from titration to titration, it is important that the potentiostat of the polarograph be very stable to achieve linearity in the endpoint current readings.

All weighings were performed on a $20 \mathrm{~g}$ capacity microbalance and were precise to $0.003 \mathrm{mg}$. The weights of all samples were corrected for air buoyancy.

Either nitrogen or argon was passed through the supporting electrolyte prior to and during the titration to keep atmospheric oxygen out of the cell. This purging gas was purified and conditioned by bubbling it through a chromous sulfate solution and then through a tower containing $9 \mathrm{~mol} / \mathrm{L} \mathrm{H}_{2} \mathrm{SO}_{4}$. 


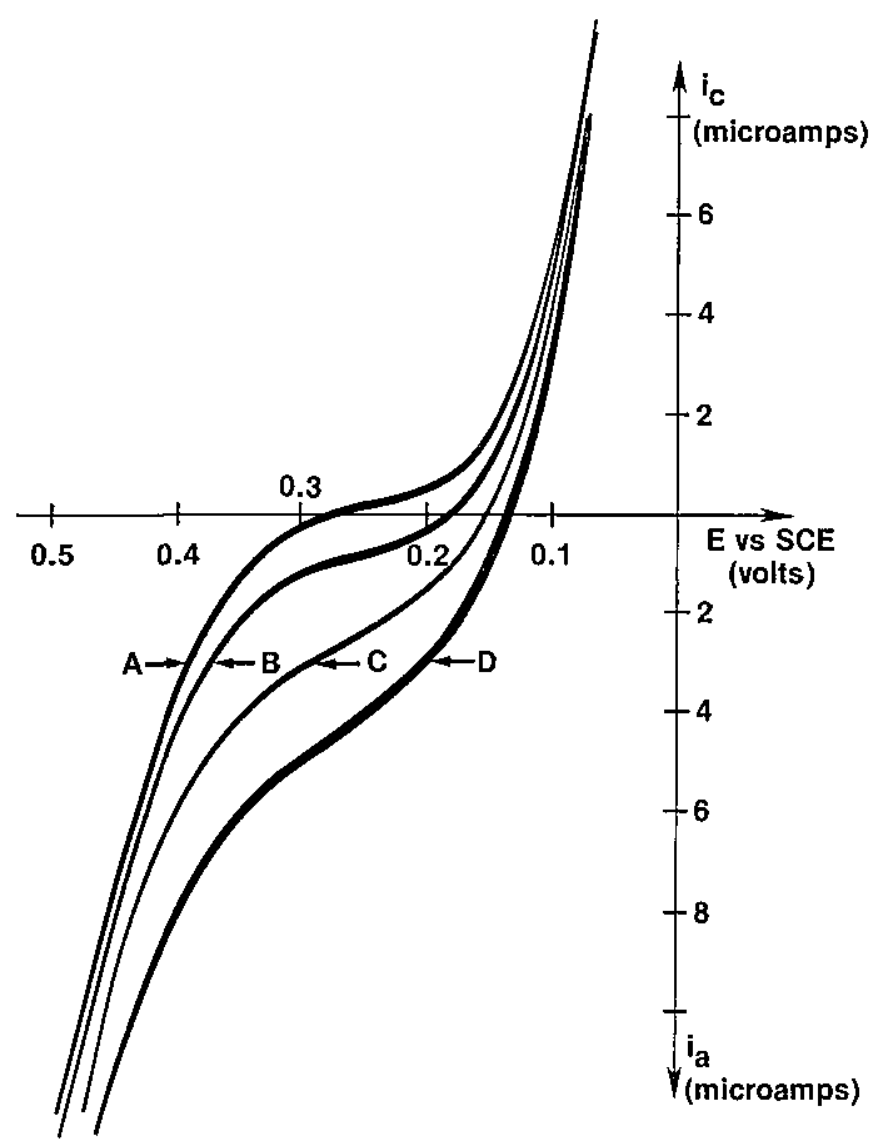

Figure 1. Current-voltage curves. Platinum indicator electrode vs. SCE reference electrode in coulometric titration cell. Supporting electrolyte: $9 \mathrm{~mol} / \mathrm{L} \mathrm{H}_{2} \mathrm{SO}_{4}, 1 \mathrm{~mol} / \mathrm{L} \mathrm{Ti}(\mathrm{IV}), 0.1 \mathrm{~g} \mathrm{Fe}\left(\mathrm{NH}_{4}\right)_{2}\left(\mathrm{SO}_{4}\right)_{2}$, $100 \mu \mathrm{eq} \mathrm{U.} \mathrm{(A)} \mathrm{at} \mathrm{endpoint.} \mathrm{(B)} 20 \mu \mathrm{eq}$ excess of Ti(III). (C) $50 \mu \mathrm{eq}$ excess of Ti(III). (D) $80 \mu \mathrm{eq}$ excess of Ti(III).

\subsection{Reagents}

The uranium which was assayed in this work was of two forms: the pure metal cast in dingots, one lot of which became Standard Reference Material 960; and the oxide of uranium of nominal stoichiometry $\mathrm{U}_{3} \mathrm{O}_{8}$ including samples of SRM 950a and SRM 950b.

The supporting electrolyte in the cathode compartment was a solution of $9 \mathrm{~mol} / \mathrm{L}$ sulfuric acid and $1 \mathrm{~mol} / \mathrm{L}$ titanyl sulfate. It was prepared according to the following procedure: purified liquid titanium tetrachloride is partially hydrolyzed ( $50 \%$ by weight) by slowly adding it to distilled water which is being well stirred and cooled in an ice-bath. The reaction is vigorous and exothermic. It must be carried out in a fume hood, because hydrogen chloride gas is liberated. The resulting solution is approximately 2.6 molal Ti(IV). This hydrolyzed titanium solution is then added slowly to concentrated (95\%) sulfuric acid (ACS reagent-grade) ( $750 \mathrm{~g}$ Ti(IV) solution per liter of sulfuric acid). Once again $\mathrm{HCl}$ is evolved rather vigorously. When addition is complete, the solution is purged with nitrogen to remove all traces of HCl. A clear solution should result. Dilute with distilled water such that the final solution is $9 \mathrm{~mol} / \mathrm{L} \mathrm{H}_{2} \mathrm{SO}_{4}$ and $1 \mathrm{~mol} / \mathrm{L} \mathrm{Ti(IV).} \mathrm{[Note:} \mathrm{After} \mathrm{several}$ weeks, a white precipitate of $\mathrm{TiO}_{2}$ will form due to the hydrolysis of the titanyl sulfate. Since this effectively depletes the Ti(IV) available for reaction, the solution should be discarded and fresh electrolyte prepared.]

The acids and the hydrogen peroxide used in the dissolution of uranium were ACS-reagent grade, as was the ferrous ammonium sulfate hexahydrate used to catalyze the reduction of $\mathrm{U}(\mathrm{VI})$.

\subsection{Preparation and Dissolution of Uranium Metal}

Using bolt-cutters, the dingot is cut into pieces weighing approximately 1 gram each. Surface oxide and impurities are removed by dipping the uranium sample in $8 \mathrm{~mol} / \mathrm{L}$ $\mathrm{HNO}_{3}$ for 10 minutes, rinsing in distilled water, etching in $3 \mathrm{~mol} / \mathrm{L} \mathrm{HCl}$ for 5 minutes, rinsing in distilled water, and drying in a vacuum desiccator. The sample is weighed on a calibrated analytical balance before the oxide reappears, correcting for the buoyancy of air (density of uranium, $19.05 \mathrm{~g} / \mathrm{cm}^{3}$ ). The sample is placed into a 125 $\mathrm{mL}$ Erlenmeyer flask and dissolved slowly in $2-10 \mathrm{~mL}$ of $6 \mathrm{~mol} / \mathrm{L} \mathrm{HCl}$, warming if necessary on a hot plate. It has been found most convenient to rest the flask in an inclined position in a small crystallizing dish throughout the dissolution process. An inverted $50 \mathrm{~mL}$ beaker is placed over the top of the flask to catch any possible spattering. After the metal has dissolved and only a small amount of black residue remains, $2 \mathrm{~mL}$ of $16 \mathrm{~mol} / \mathrm{L} \mathrm{HN0}_{3}$ are slowly added to oxidize all of the uranium to the hexavalent state, $\mathrm{U}(\mathrm{VI})$. The black residue will also dissolve. The beaker serving as the splash guard is rinsed with 5 $\mathrm{mL}$ of distilled water, this water being added to the sample flask. The walls of the flask are then rinsed with 5 $\mathrm{mL}$ of distilled water. Next, $5 \mathrm{~mL}$ of concentrated $\mathrm{H}_{2} \mathrm{SO}_{4}$ $(95 \%)$ are carefully added to the sample. The solution is then evaporated down to $\mathrm{SO}_{3}$ fumes three times with the addition of $5 \mathrm{~mL}$ of water after each fuming. It is imperative that all traces of chloride and nitrate be removed from the solution. (Nitrate is reduced at the cathode and as such would pose a serious interference in the subsequent coulometric titration.)

To avoid the repetitive fumings required to eliminate nitrate, hydrogen peroxide can be used instead of nitric acid to oxidize the uranium. With this procedure, after the metal has dissolved in $\mathrm{HCl}, 1 \mathrm{~mL}$ of $\mathrm{H}_{2} \mathrm{O}_{2}(30 \%)$ is added slowly. A light yellow precipitate (a peroxide of uranium) may form but is unstable and is rapidly reduced back to $U(V I)$ upon heating, resulting in a clear brilliant yellow solution. To destroy the excess hydrogen 
peroxide the solution is evaporated nearly to dryness. The sides of the flask are then rinsed with distilled water and $5 \mathrm{~mL}$ of $\mathrm{H}_{2} \mathrm{SO}_{4}(95 \%)$ are added to the solution. The solution is then evaporated to $\mathrm{SO}_{3}$ fumes. If allowed to stand a day or two, a crystalline percipitate may appear. Distilled water should be added to redissolve the precipitate, with subsequent evaporation to $\mathrm{SO}_{3}$ fumes again before analyzing.

Blanks containing the same volumes of reagents used in the dissolution of the uranium samples were put through the same evaporation procedure. To some of these blank samples were added $30.31 \mu \mathrm{eq}$ of uranium from a stock solution.

\subsection{Preparation and Dissolution of Uranium Oxide $\left(\mathrm{U}_{3} \mathrm{O}_{8}\right)$}

A sample of the uranium oxide (approximately $1.5 \mathrm{~g}$ ) is placed in a platinum boat and ignited in a furnace for 1 hour at $900^{\circ} \mathrm{C}$ (SRM 950b was fired at $800^{\circ} \mathrm{C}$ ). After the firing process, the sample is allowed to cool for 15 minutes, and stored in a desiccator. After cooling, the boat plus sample is weighed on a calibrated analytical balance, the sample is dumped from the boat into a 125 $\mathrm{mL}$ Erlenmeyer flask, and the empty boat is reweighed. The mass of the sample is calculated by difference, corrected for the buoyancy of air (density of uranium oxide $8.3 \mathrm{~g} / \mathrm{cm}^{3}$ ). The sample is digested in $10 \mathrm{~mL}$ of $12 \mathrm{~mol} / \mathrm{L} \mathrm{HCl}$ on a warm hotplate overnight $(8$ to 12 hours). Care should be taken to avoid evaporating the solution to dryness. As described earlier, the flask is in an inclined position with a beaker over the top. After the uranium oxide sample is dissolved (some black residue may remain), the sample is carried through the oxidation and fuing procedures outlined in section 3.3. Either nitric acid or hydrogen perioxide may be used, with the latter being preferred.

\subsection{Coulometric Titration}

Prior to delivery of the sample, $75 \mathrm{~mL}$ of supporting electrolyte are added to the cathode chamber of the cell togetehr with $100 \mathrm{mg}$ of ferrous ammonium sulfate hexahydrate. Nitrogen or argon is then passed through the compartment and into the chamber for one-half hour to remove air. After purging, the catholyte is permitted to flow into the intermediate compartments to the extent that it just covers the bottom of each compartment, thus establishing electrolytic connection between the anode and cathode chambers.

A small amount of uranyl sulfate solution, about $5 \mu \mathrm{eq}$, is then added to the cathode chamber and is pre-titrated by passage of small increments of charge equivalent to 1 eq using 3-10 mA. At the conclusion of each increment, the amperometric indicator current is recorded. This current, small and essentially constant up to the equivalence point, exhibits a curvature in the vicinity of the equivalence point and becomes a linear function of the concentration beyond the equivalence point. After the first excess of Ti(III) is noted, the solution is permitted to equilibrate for one-half hour, after which increment-wise generation is resumed. The linear portion of the indicator current is extrapolated graphically and its intersection with the zero-current line is taken as the endpoint.

After completion of the pre-titration, the intermediate cell chambers are rinsed by repeatedly emptying and filling the chambers with electrolyte, applying suction or nitrogen pressure as required. The final reading of the indicator current is recorded and this reading is used to determine the amount of overtitration of the pre-titration step.

Following the pre-titration, the intermediate compartments are completely filled with catholyte and the sample, which has been deaerated, is delivered into the cathode chamber by applying nitrogen pressure to a specially designed polyethylene siphon system.

The sample is titrated using $101 \mathrm{~mA}$ current for a precalculated period of time corresponding to a few microequivalents in excess of the stoichiometric amount. The middle compartments are again emptied into the cathode chamber using nitrogen pressure. The sample flask, which is still connected to the cathode chamber through the siphone tude, is rinsed several times with the catholyte by alternately applying vacuum and pressure to the siphon system.

Following the one-half hour equilibration period, small increments of charge are again passed as already described in the pre-titration procedure and the indicator current is recorded after each addition. The indicator current curve is again extrapolated to locate the virtual endpoint. The charge required to reduce the uranium is the amount to the endpoint plus the excess resulting from the preceding pre-titration.

\section{Results and Discussion}

As in any precise chemical analysis, it was necessary to determine the blank resulting from reagents used in the sample preparation. It is quite apparent that any of the ions which are reducible by Ti(III) will be titrated along with uranium, yielding high results. It should be noted, however, that reducible impurities in the supporting electrolyte do not contribute to the overall blank since they are removed in the pre-titration step.

To evaluate the bias arising from chemical treatment of the sample, a number of titrations were made of samples containing $30.31 \mu \mathrm{eq}$ of uranium which had been 
processed with the same quantities of acids as in the larger sample preparation. The results for titrations of 11 aliquot samples gave a blank value of $+0.27 \mu \mathrm{eq} \pm 0.17 \mu \mathrm{eq}$. In addition, a study was made of the relationship between the sample size and the assay. This study indicated a systematic increase of the assay value as the sample size decreased. The plot of the difference between the calculated and found number of equivalents verses sample size for 30 determinations of the uranium content in dingot metal yields a linear relationship that, upon extrapolation to zero sample size, gives an intercept close to $0.35 \mu \mathrm{eq}$ (Fig. 2), well within the uncertainty of the value obtained in the blank titrations. On the basis of these two pieces of experimental evidence, a $0.27 \mu \mathrm{eq}$ bias must be subtracted from all titrations.

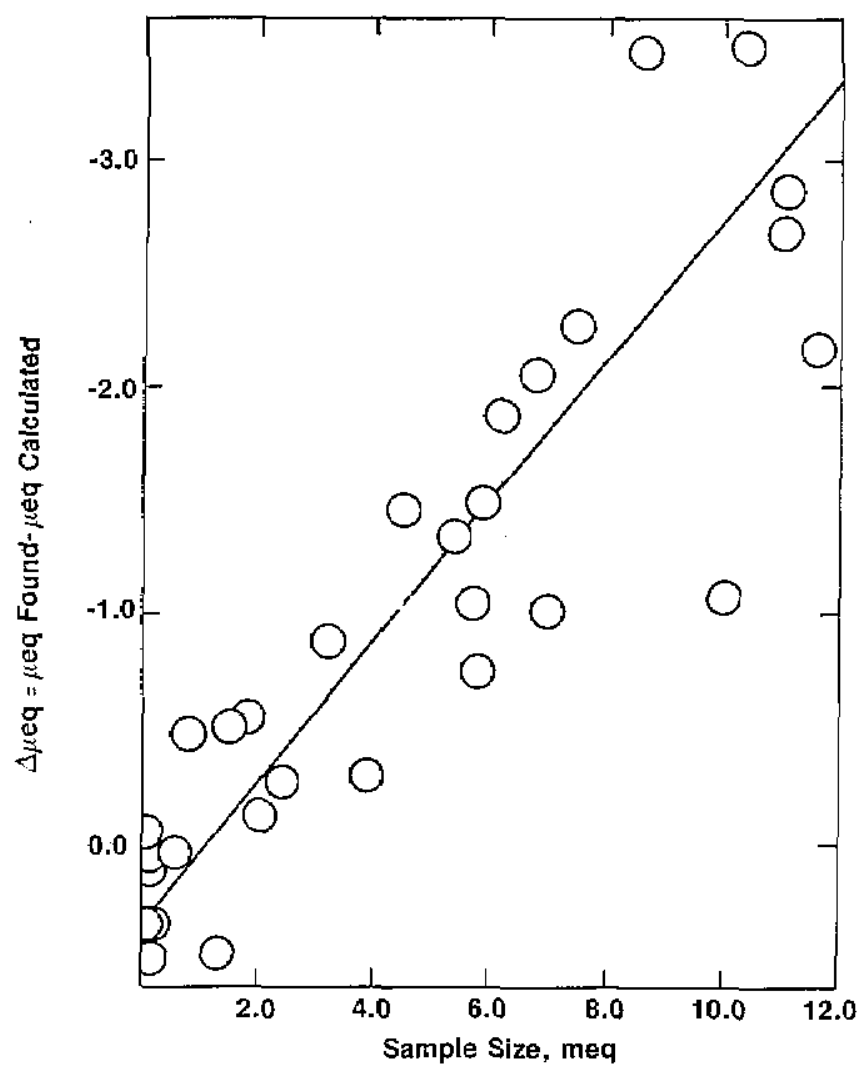

Figure 2. Analysis of titration data for bias.

A summary of the titration data of dingot uranium, corrected for the bias, is given in Table 1. The data were subdivided into four groups, encompassing different sample sizes: Group I - up to $100 \mathrm{mg}$ of U; Group II - 100 to $500 \mathrm{mg}$ of U; Group III -500 to $100 \mathrm{mg}$ of $\mathrm{U}$; and Group IV - higher than $1000 \mathrm{mg}$ of $\mathrm{U}$. The table summarizes individual results, along with the respective averages, and the corresponding standard deviation of a single determination for each group. It
TABLE 1. Assay in weight percent, of dingot uranium in method development.

\begin{tabular}{|c|c|c|c|c|}
\hline \multicolumn{5}{|c|}{ Average Sample, Size, mg } \\
\hline & 50 & 300 & 750 & 1010 \\
\hline & $\begin{array}{r}100.18 \\
100.15 \\
99.31 \\
99.95 \\
99.88 \\
100.18 \\
99.91 \\
99.96\end{array}$ & $\begin{array}{l}99.966 \\
99.957 \\
99.977 \\
99.970 \\
99.966 \\
99.971 \\
99.982 \\
99.982 \\
99.978 \\
99.983 \\
99.974 \\
99.968 \\
99.975 \\
99.969 \\
99.965 \\
99.982\end{array}$ & $\begin{array}{l}99.964 \\
99.954 \\
99.977 \\
99.964 \\
99.980 \\
99.948 \\
99.985 \\
99.962 \\
99.947 \\
99.984 \\
99.976 \\
99.974 \\
99.993\end{array}$ & $\begin{array}{l}99.964 \\
99.979 \\
99.972 \\
99.973 \\
99.987\end{array}$ \\
\hline $\begin{array}{l}\text { Average } \\
\text { Std. Dev. }\end{array}$ & $\begin{array}{r}99.94 \\
0.29\end{array}$ & $\begin{array}{r}99.973 \\
0.008\end{array}$ & $\begin{array}{r}99.970 \\
0.015\end{array}$ & $\begin{array}{r}99.975 \\
0.009\end{array}$ \\
\hline
\end{tabular}

can be seen that for larger samples, the precision remains constant.

It should be kept in mind that the assay reported here represents the reductometric value for the material, and as such would include iron and any other impurities in the uranium which would be reduced by trivalent titanium.

Uranium metal, issued by NBS as SRM 960, was analyzed independently by two analysts who used this method. The results are shown in table 2. Excellent agreement is obtained between the two analyses, indicating no operator bias. A correction of -0.0108 weight percent must be applied to this reductometric assay due to two electroactive impurities known to be present, 42.1 ppm iron and $4 \mathrm{ppm}$ vandium. Thus this material is certified at 99.975 weight percent uranium.

Table 2, Analysis of uranium metal, SRM 960. (uncorrected for impurities, see text)

\begin{tabular}{lcccc}
\hline & $\begin{array}{c}\text { Number of } \\
\text { Determinations }\end{array}$ & $\begin{array}{c}\text { Atomis Weight of } \\
\text { Analyst }\end{array}$ & $\begin{array}{c}\text { Assay } \\
\text { Uram in Sample }\end{array}$ & $\begin{array}{c}\text { Standard } \\
\text { Weight Percent Deviation }\end{array}$ \\
\hline A & 21 & 238.0289 & 99.9855 & 0.0081 \\
B & 4 & 238.0289 & 99.9848 & 0.0038 \\
\hline
\end{tabular}

The developed method of analysis was also used for the assay of various $\mathrm{U}_{3} \mathrm{O}_{8}$ preparations. The values obtained for these materials are summarized in table 3 . SRM 950a and SRM 950b are of natural uranium isotopic composition and are issued by NBS as chemical standards 
TABLE 3. Analysis of Uranium Oxide, $\mathrm{U}_{3} \mathrm{O}_{8}$.

\begin{tabular}{lcccc}
\hline \hline Material & $\begin{array}{c}\text { Number of } \\
\text { Determinations }\end{array}$ & $\begin{array}{c}\text { Atomic Weight of } \\
\text { Uranium in Sample }\end{array}$ & $\begin{array}{c}\text { Assay } \\
\text { Weight Percent }\end{array}$ & $\begin{array}{c}\text { Standard } \\
\text { Deviation }\end{array}$ \\
\hline SRM & 3 & 238.03 & 99.923 & 0.023 \\
SRM 950b & 6 & 238.03 & 99.958 & 0.022 \\
$\begin{array}{l}\text { Depleted } \\
\quad \begin{array}{l}\text { Secondary } \\
\text { Depleted } \\
\quad \text { Primary }\end{array}\end{array}$ & 3 & 238.050 & 99.929 & 0.027 \\
$\begin{array}{c}\text { Enriched } \\
\text { Primary }\end{array}$ & 3 & 238.051 & 99.921 & 0.009 \\
\hline
\end{tabular}

for uranium analyses. The other materials are for use in the preparation of uranium isotopic standards. The atomic weights were calculated from the isotopic abundances of uranium in the various samples. All of the materials were "pure" in that the total of metallic impurities did not exceed 0.01 percent.

\section{Summary}

An improved method for the coulometric assay of uranium and uranium oxide has been developed based on the electrogeneration of titanous ion in sufluric acid. Ferrous ion is used as a catalyst. The endpoint using an amperometric system is determined by extrapolation after a slight overtitration which increases the reaction rate and guarantees complete reaction. Hydrogen peroxide is employed as the oxidant in the dissolution procedure in lieu of nitric acid which if not completely destroyed would greatly interfere with the subsequent coulometric titration. The method has been applied to the analysis of several preparations of uranium metal and uranium oxide, including SRM's. The demonstrated precision for the assay of the metal as represented by the standard deviation of the individual measurement ranges from 0.004 to 0.008 weight percent, and that for the assay of the oxide from 0.006 to 0.027 weight percent.

\section{Acknowledgments}

The authors wish to express their gratitude to L. A. Machlan and J. R. Moody for their help in the heat treatment of the uranium oxide samples, to $E$. J. Maienthal for her work in the polarographic analysis of the impurities in the metal, to J. K. Taylor for many meaningful discussions, and to the Office of Standard Reference Materials, NBS, for their support in this project.

\section{References}

[1] Craig, D. N.; Hoffman, J. I.; Law, C. A. Hamer, W. J. Determination of the value of the Faraday with a silver-prechloric acid coulometer. J. Res. Natl. Bur. Stand. (U.S.). 64A(5): 381-402; 1960 September-October.

[2] Marinenko, G; Taylor, J. K. Electrochemical equivalents of benzoic acid and oxalic acid. Anal. Chem. 40(11), 1645-1651; 1968 September.

[3] Koch, W. F. The value of the Faraday via 4-aminopyridine. In Atomic Masses and Fundamental Constants 6, J. A. Nolen, Jr. and W. Benenson, ed. New York, NY: Plenum Publishing Corp.; 1980, 167-172.

[4] Bower, V. E.; Davis, R. S.; Murphy, T. J.; Paulsen, P. J.; Gramlich, J. W.; Powell, L. J. Recalculation of the Faraday constant due to a new value for the atomic weight of silver. J. Res. Natl. Bur. Stand. (U.S.). 87(1): 21-22; 1982 January-February,

[5] Taylor, J. K.; Smith, S. W. Precise coulometric titration of acids and bases. J. Res. Natl. Bur. Stand. (U.S.). 63A(2): 153-159; 1959 September-October.

[6] Marinenko, G.; Taylor, J. K. Precise coulometric titration of halides. J. Res. Natl. Bur. Stand. (U.S.). 67A(1): 31-35; 1963 January-February.

[7] Marinenko, G.; Taylor, J. K. Precise coulometric titrations of potassium dichromate. J. Res. Natl. Bur. Stand. (U.S.) 67A(5): 453-459; 1963 September-October.

[8] Taylor, J.K.; Marinenko, G. High-precision coulometric titrations with special reference to the determination of uranium. Proceedings of the conference on high-precision analysis of substances of interest to nuclear energy. EURATOM; Brussels, Belgium 1965. 147-153.

[9] Rodden, C. J.; Warf, J. C. Uranium, chapter 1 in Analytical Chemistry of the Manhattan Project. C. J. Rodden, ed. New York, NY: McGraw-Hill Book Company, Inc.; 1950. 3-159.

[10] Kramer, H. Determination of uranium with high precision, New Brunswick Laboratory Report; 1960, May. 20 p.

[11] Voss, F. S.; Green, R. E. A precision potentiometric titration method for the determination of uranium. Atomic Energy Commission (U.S.). AEC Report 4030; 1955. 11 p.

[12] Vita, O. A.; Trivisonno, C. F.; Walker, C. R. An improved titrimetric method for the precise determination of uranium. Goodyear Atomic Corp. Report. GAT-471 Chemistry; 1962 November. $10 \mathrm{p}$.

[13] Duckitt, J. A.; Goode, G. C. A method for high-precision assay of uranium metal. Analyst. 87(1031), 121-124; 1962 February.

[14] Pszonicki, L. Precise titrimetric determinations of uranium in high-purity uranium compounds. Talanta 13(3), 403-408; 1966 March.

[15] Arthur, P.; Donahue, J. F. Titanic chloride as an intermediate in coulometric analyses. Anal. Chem. 24(10), 1612-1614; 1952 October.

[16] Malmstadt, H. V.; Roberts, C. B. Automatic spectrophotometric titration with coulometrically generated titanous ion. Anal. Chem. 27(5), 741-744; 1955 May.

[17] Parsons, J. S.; Seaman, W. Coulometric titration of dyes with externally generated titanous ion. Anal. Chem. 27(2), 210-212; 1955 February.

[18] Lingane, J. J.; Iwamoto, R. T. Coulometric titration of uranium with electrogenerated titanous ion. Anal. Chim. Acta. 13(5), 465-472; 1955 November. 
[19] Lingane, J. J.; Kennedy, J. H. Coulometric titration of iron, cerium and vanadium with titanous ion. Anal. Chim. Acta. 15(5), 465-472; 1956 November.

[20] Kennedy, J. H.; Lingane, J. J. Coulometric titration of uranium and uranium-vanadium mixtures with +3 titanium. Anal. Chim. Acta. 18(3), 240-244; 1958 March.

[21] Marinenko, G; Taylor, J. K. High-precision coulometric iodimetry. Anal. Chem. 39(13), 1568-1571; 1967 November.
[22] Marinenko, G. On the atommic weight of gallium. J. Res. Natl. Bur. Stand. (U.S.). 81A(1): 1-4; 1977 January-February.

[23] Marinenko, G. Absolute determination of the electrochemical equivalent and the atomic weight of zinc. Method, apparatus, and preliminary experiments. J. Res. Natl. Bur. Stand. (U.S.). 79A(6): 737-745; 1975 November-December.

[24] Koch, W. F.; Diehl, H. Additional results on the value of the Faraday. Talanta 23(7), 509-512; 1976 July. 